\title{
Investigating the regulatory role of ORMDL3 in airway barrier dysfunction using in vivo and in vitro models
}

\author{
RUIXUE YANG $^{1 *}$, MIN TAN $^{1 *}$, JIANYA XU $^{2}$ and XIA ZHAO ${ }^{1-3}$ \\ ${ }^{1}$ Nanjing University of Chinese Medicine; ${ }^{2}$ Jiangsu Key Laboratory of Pediatric Respiratory Disease, Nanjing, \\ Jiangsu 210023; ${ }^{3}$ Jiangsu Province Hospital of Chinese Medicine, Nanjing, Jiangsu 210029, P.R. China
}

Received December 14, 2018; Accepted June 4, 2019

DOI: $10.3892 /$ ijmm.2019.4233

\begin{abstract}
The airway epithelium (AE) is the main protective barrier between the host and external environmental factors causing asthma. Allergens or pathogens induce AE dysfunction, including epithelial permeability alteration, trans-epithelial electrical resistance (TEER) reduction, upregulation of inflammatory mediators and downregulation of junctional complex molecules. Orosomucoid-like protein isoform 3 (ORMDL3), a gene closely associated with childhood onset asthma, is involved in airway inflammation and remodeling. It was hypothesized that ORMDL3 plays an important role in regulating AE barrier function. In vivo [chronic asthma induced by ovalbumin-respiratory syncytial virus (OVA-RSV)] in mice) and in vitro (human bronchial epithelial cells and $16 \mathrm{HBE}$ cells) models were used to assess ORMDL3's role in AE function regulation, evaluating paracellular permeability, TEER and the expression levels of junctional complex molecules. The effects of ORMDL3 on the extracellular signal-regulated protein kinase (ERK) pathway were determined. In mice with OVA-RSV induced chronic asthma, ORMDL3 and sphingosine kinase 1 (SPHK1) were upregulated whereas the junction related proteins Claudin-18 and E-cadherin were downregulated. Overexpression of ORMDL3 resulted in decreased TEER, downregulation of junctional complex molecules and induced epithelial permeability. In contrast, ORMDL3 inhibition showed the opposite effects. In 16HBE cells, ORMDL3 overexpression induced SPHK1 distribution and activity, while SPHK1 inhibition resulted in increased TEER upon administration of an ORMDL3 agonist or ORMDL3 overexpression. In addition, ERK activation occurred downstream of SPHK1
\end{abstract}

Correspondence to: Dr Xia Zhao, Jiangsu Province Hospital of Chinese Medicine, 155 Hanzhong Road, Nanjing, Jiangsu 210029, P.R. China

E-mail: zhaoxiahy@126.com

*Contributed equally

Key words: asthma, airway barrier, orosomucoid-like protein isoform 3, sphingosine kinase 1/extracellular signal-regulated protein kinase activation in $16 \mathrm{HBE}$ cells. High levels of ORMDL3 result in damaged AE barrier function by inducing the SPHK1/ERK pathway.

\section{Introduction}

Asthma represents a chronic respiratory disease that affects more than 300 million individuals worldwide (1). It is characterized by airway inflammation, hyperresponsiveness and remodeling (2). As the first line of contact with the external environment, airway epithelial (AE) cells form a barrier to the outside world comprising airway surface fluids, mucus and apical junctional complexes (AJCs) between neighboring cells. Previous studies have focused on AE barrier injury in asthma (3-5), reporting dysfunctional epithelial AJCs in asthmatic airways, without describing the precise mechanisms and/or consequences for airway inflammation (6,7). Impaired epithelium could increase airway vulnerability to insults from viruses, allergens and toxic substances, aggravating airway inflammation and remodeling. Due to ethical constraints, animal models serve as a golden tool for understanding the pathology of asthma in vivo. However, most animal studies have used acute sensitization and exposure to allergens. In addition, the available models often lack features of chronic remodeling. Therefore, the potential mechanisms obtained in mouse studies are merely used to understand the effects of particular therapies in acute allergic inflammation and do not comprehensively explain the chronic phase of the disease.

In the past decades, increasing attention has been paid to the management of childhood asthma. The orosomucoid-like protein isoform 3 (ORMDL3) gene is strongly and significantly associated with childhood-onset asthma (8). Several in vitro and in vivo studies have suggested that ORMDL3 contributes to airway remodeling and inflammation by selectively activating the unfolded protein response in the endoplasmic reticulum $(9,10)$, regulating chemokine expression (11) and altering $\mathrm{Ca}^{2+}$ influx for T-lymphocyte activation (12). Previous findings indicated that intranasal administration of cytokines significantly induces ORMDL3 mRNA expression in the bronchial epithelium of mice (9). Previously, ORMDL3 was shown to regulate the metabolism of the cell membrane component sphingolipid in A549 cells $(13,14)$. Sphingolipid has attracted increasing attention in recent years. Indeed, several studies have established its role in cell growth, survival 
and migration (15-17). ORMDL3 is involved in sphingolipid metabolism and de novo sphingolipid synthesis (9). An in vitro study revealed ORMDL3 overexpression at mid-levels inhibits serine palmitoyltransferase (SPT) activity, while a more pronounced ORMDL3 overexpression results in increased SPT levels (18).

As a key lipid kinase in sphingolipid metabolism, sphingosine kinase 1 (SPHK1) regulates sphingosine 1-phosphateas well as the SPT balance in the lung tissue. SPHK1 mRNA levels are significantly increased in airway diseases such as lung cancer, rhinitis and asthma (19-21). Previous studies have proposed that SPHK1 is associated with airway inflammation, goblet cell hyperplasia and hyperresponsiveness $(19,22,23)$. The possible mechanisms include calcium flux control, arachidonic acid release and ERK phosphorylation induction (24-26). In vivo studies have demonstrated that treatment with an SPHK1 inhibitor or SPHK1 knockout could ameliorate OVA-induced airway hyperreactivity (AHR) and airway inflammation in mice $(22,26)$. Meanwhile, SPHK1 suppression upregulates E-cadherin in A549 cells (17). Based on these data, it was hypothesized that ORMDL3 overexpression causes AE barrier injury by activating SPHK1.

\section{Materials and methods}

Animal sensitization and challenge. A total of 12 female $\mathrm{Balb} / \mathrm{c}$ mice (4 weeks old, 18-22 g) were obtained from Beijing Vital River Laboratory Animal Technology Co., Ltd. Animals were housed in the experimental animal center of the Nanjing University of Chinese Medicine, with a $12 \mathrm{~h}$ light/dark cycle at a constant temperature of $22 \pm 2^{\circ} \mathrm{C}$ and a relative humidity of $50 \%$. Cages, bedding, food and water were sterilized before use and animals received ad libitum access to food and water. The animals were acclimatized for 7 days prior to initiating the experiments. The animals were immunized with $200 \mu 1$ of $2.5 \%$ ovalbumin (OVA; Sigma-Aldrich; Merck KGaA) in saline by intraperitoneal injection on days 1 and 8 (sensitization stage). On days 15-28, mice were exposed to $2.5 \%$ OVA by inhalation for $30 \mathrm{~min}$ per day (acute challenge stage). On days 32-85, the animals were further exposed to aerosolized $2.5 \%$ OVA for $30 \mathrm{~min}$ once every three days (chronic challenge stage). On days 29, 42 and 55, mice were anesthetized by inhaled ether; when the mouse's breathing became slow and deep, and loss of righting reflex, it ensured the mouse was fully anesthetized, and then $50 \mu \mathrm{l}$ respiratory syncytial virus was administered (RSV; $10^{3.015} \mathrm{TCID}_{50} / 50 \mu \mathrm{l}$ ) by the intranasal route(virus infection stage). Control mice were administered normal saline instead of OVA and RSV in the sensitization, challenge and virus infection stages of the protocol. Human RSV (A2 strain, purchased from the Type Culture Collection Center of Wuhan University) was amplified as previously described (27). Titers were determined by the $\mathrm{TCID}_{50}$ method in Hep-2 cells (CBP60246; Type Culture Collection of the Chinese Academy of Sciences). The protocols for sensitization, challenge and virus infection are summarized in Fig. 1A. The animal experiments were performed according to the National Institutes of Health Guidelines for Laboratory Animals and approved by the Animal Ethics Committee of Nanjing University of Chinese Medicine.
Lung tissue collection and histopathology. On day 86, mice were anesthetized by chloral hydrate $(400 \mathrm{mg} / \mathrm{kg})$, the right eyeball was removed to collect blood $(\sim 1.0 \mathrm{ml})$ and sacrificed by cervical dislocation. When the mice no longer moved, exhibited no response to external stimuli and breathing and cardiac arrest, the mice were confirmed as dead. Then, the lungs were removed from the thoracic cavity by careful dissection, inflated with $1 \mathrm{ml}$ of $10 \%$ neutral-buffered formalin and fixed with $10 \%$ neutral-buffered formalin at room temperature for $72 \mathrm{~h}$. After fixation, the left lung was dissected, embedded in paraffin and sectioned at $6 \mu \mathrm{m}$. The resulting sections were stained with hematoxylin-eosin (H\&E) at room temperature for $3 \mathrm{~min}$. Total lung inflammation was defined as the sum of peri-bronchial and peri-vascular scores (Table SI). Mucus production and goblet cell hyperplasia were examined by periodic acid-Schiff (PAS) staining as described previously (28). Sections stained (at room temperature for $15 \mathrm{~min}$ ) with the Masson's trichromedye were required to include the extracellular matrix (ECM) and contractile elements associated with the airway. Peri-bronchiolar areas positive for Masson's trichrome staining were determined by light microscopy with an Image-Pro Plus V6.0 image analysis system (Media Cybernetics, Inc.).

Quantification of cytokine levels. Lung tissue and serum cytokine levels were assessed with ELISA kits specific for mouse interleukin (IL)-4(MM-0173M2), IL-13 (MM-0165M2), and tumor necrosis factor (TNF)- $\alpha$ (MM-0132M2; all, Feiya Biotechnology). The assays were performed according to the manufacturer's protocol.

Cell Counting Kit (CCK)-8 assay for TNF-a concentration selection. To quantitate any cytotoxic effects of TNF- $\alpha$, a CCK-8 cell viability detection assay was performed on the conditioned media from 16HBE cells according to the manufacturer's protocol (Dojindo Molecular Technologies, Inc.). Briefly, CCK-8 (10 $\mu \mathrm{l})$ was added to each well and the plates were incubated for $2 \mathrm{~h}$ at $37^{\circ} \mathrm{C}$. Optical density was measured using a Microplate Reader at $450 \mathrm{~nm}$.

Cell culture and treatment. Human bronchial epithelial 16HBE cells (CBP60550, purchased from the Cell Bank Center, Shanghai Institutes for Biological Sciences, Chinese Academy of Sciences) cultured in RPMI-1640 (Gibco; Thermo Fisher Scientific, Inc.) with $10 \%$ fetal bovine serum (FBS; Gibco; Thermo Fisher Scientific, Inc.) and 1\% penicillin/streptomycin (Gibco; Thermo Fisher Scientific, Inc.). All cells were maintained in a humidified chamber containing $5 \% \mathrm{CO}_{2}$ at $37^{\circ} \mathrm{C} .16 \mathrm{HBE}$ cells transfected with small interfering (si)-SPHKl/si-control (ctrl) were exposed to $10 \mathrm{ng} / \mathrm{ml}$ TNF- $\alpha$ (purchased from PeproTech, Inc.); 16HBE cells overexpressing ORMDL3 and the corresponding empty control (Vector; purchased from Applied Biological Materials Inc.) were exposed to $10 \mathrm{nM} \mathrm{N,N-dimethyl-D-erythro-sphingosine}$ (DMS; purchased from Sigma-Aldrich; Merck KGaA) for 5 days, followed by the evaluation of epithelial TEER and mRNA and protein expression levels.

siRNA preparation and transfection. For si-RNA transfection, $16 \mathrm{HBE}$ cells were seeded at a density of $2 \times 10^{5}$ cells/well in 
A

- i.p. OVA ( $100 \mu \mathrm{g}$ in $1 \mathrm{mg}$ aluminium potassium sulfate) or aluminium potassium sulfate alone

- i.n.h. OVA (2.5\%) or saline every day

$\square$ i.n.h. OVA (2.5\%) or saline every 3 days

$\nabla$ N.A. RSV $(50 \mu \mathrm{l} /$ mouse $)$

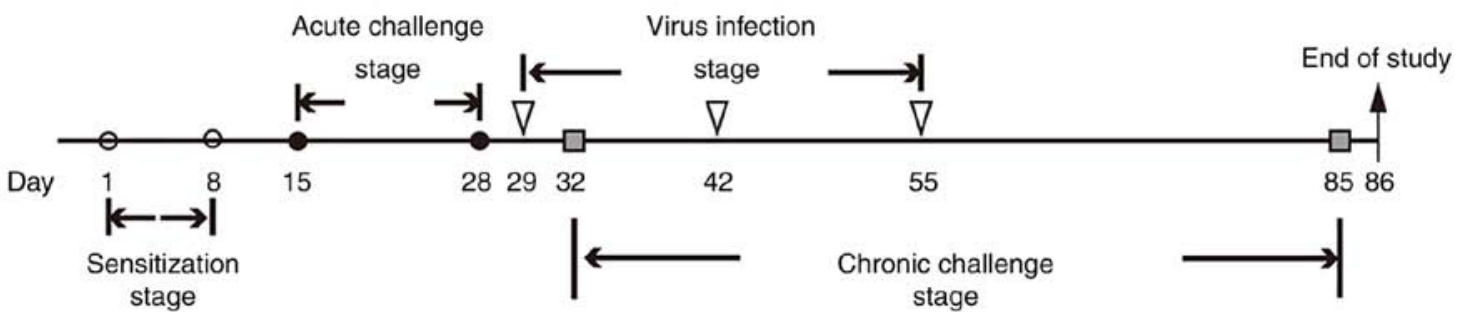

B
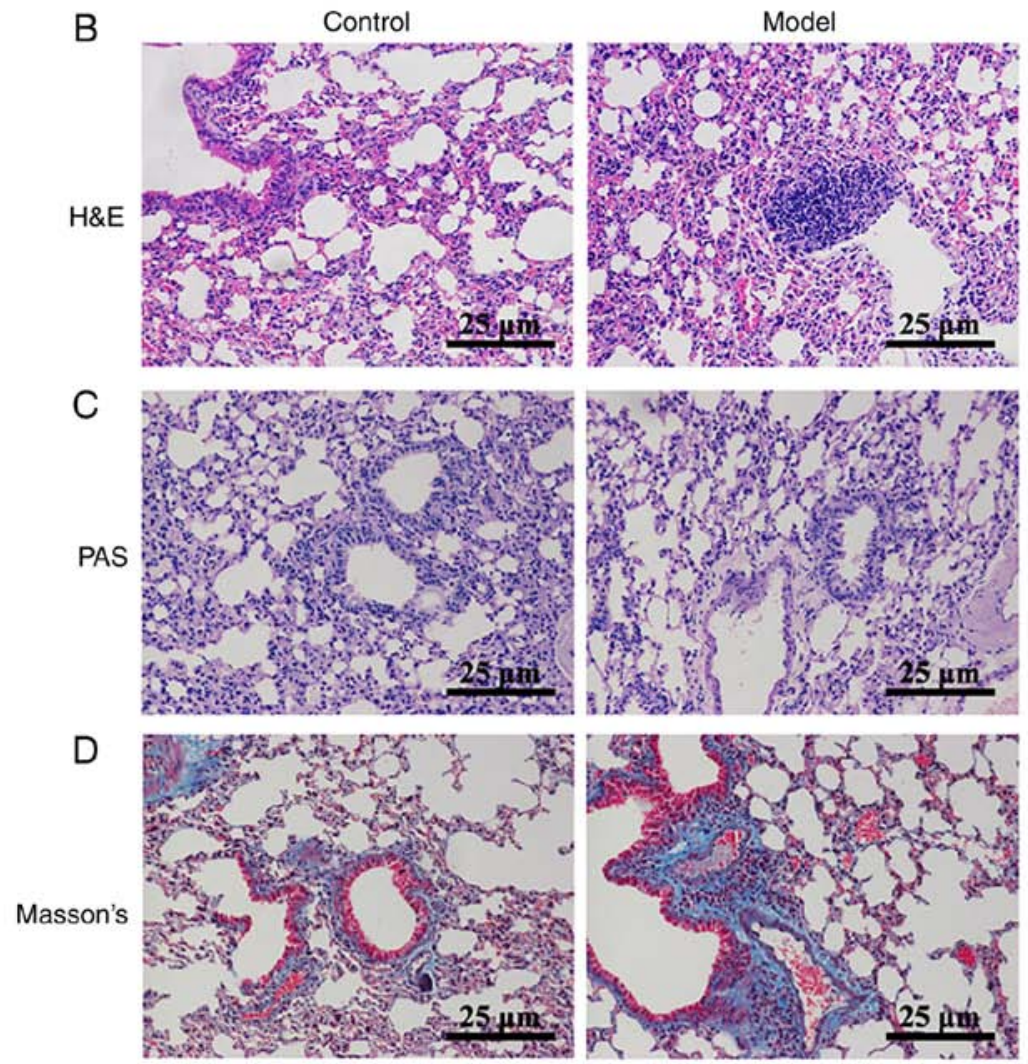

Model
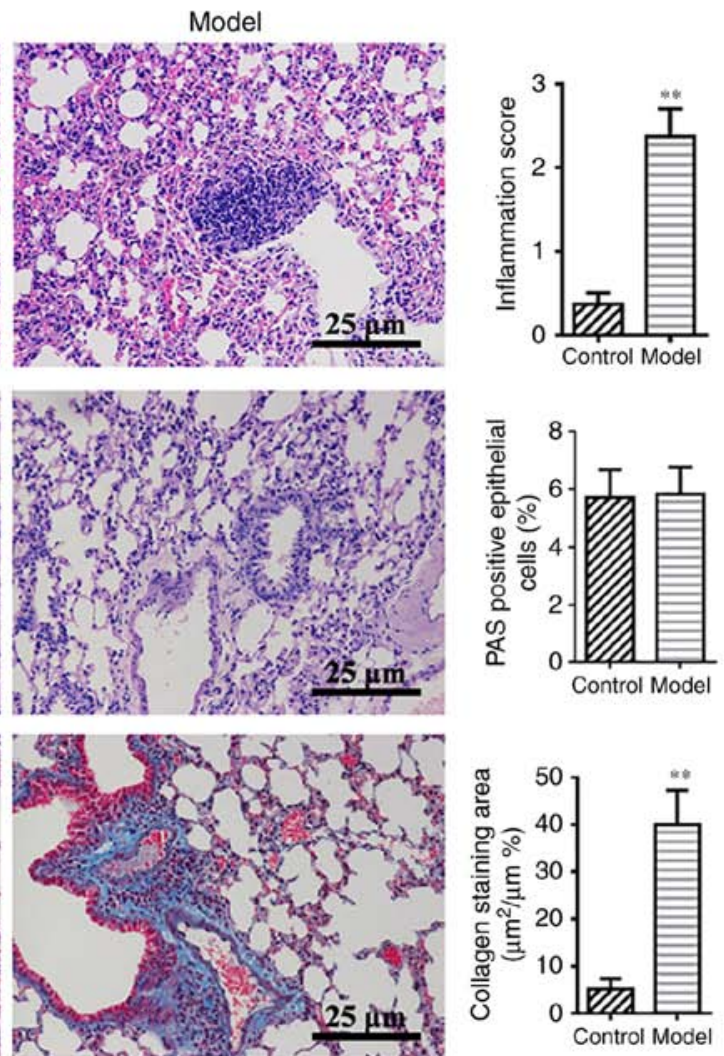

Figure 1. OVA-RSV induces mouse airway inflammation and upregulates ORMDL3 expression. (A) Outline of the establishment of a chronic asthmatic mouse model with detailed strategy for OVA-RSV administration.i.p., i.n.h. and N.A. Histological analysis of lung tissues from control and OVA-RSV mice sacrificed on day 86. (B) Lung sections were stained with H\&E to analyze the infiltration of inflammatory cells. (C) PAS staining was performed to assess goblet cell hyperplasia. (D) Masson's trichrome staining was carried out to evaluate sub-epithelial deposition of collagen and fibrosis. Values are mean \pm standard deviation ( $\mathrm{n}=6$ per group). ${ }^{* *} \mathrm{P}<0.01$ vs. control group. Magnification, $\mathrm{x} 200$. The results are representative of six independent animals. PAS, Periodic acid-Schiff; H\&E, hematoxylin-eosin; i.n.h., inhalation; i.p., intraperitoneal; N.A., intranasal; OVA-RSV, ovalbumin-respiratory syncytial virus.

6-well plates until 50-70\% confluence. The si-RNA targeting ORMDL3 (si-ORMDL3) and its negative control siRNA (si-control), and the si-RNA targeting SPHK1 (si-SPHK1) and its negative control si-RNA (si-ctrl; Synthesized by GenePharma Co., Ltd.). si-RNA was transfected into $16 \mathrm{HBE}$ cells with si-RNA-Mate (50 pmol si-RNA; $16 \mu 1$ si-RNA-Mate; GenePharma Co., Ltd.) in RPMI-1640-low serum medium in accordance with the manufacturer's protocols. The sequences of the siRNAs used are listed in Table I and activity was measured via reverse transcription-quantitative PCR
(RT-qPCR) $24 \mathrm{~h}$ after transfection. Thereafter, the transfected cells were trypsinized and seeded at a density of $0.33 \times 10^{5}$ cells per $\mathrm{cm}^{2}$ in Transwell inserts with a $0.4 \mu \mathrm{m}$ pore size (Corning, Inc.). The medium was changed the following day and subsequently refreshed every other day throughout the experiment. The silencing effects of si-RNAs were confirmed by RT-qPCR.

TEER and epithelial barrier integrity assessments. ORMDL3/Vector and si-ORMDL3/si-control cells were seeded in Transwell inserts as mentioned above, and incubated 
Table I. Sequences of si-RNAs.

\begin{tabular}{lll}
\hline Gene & \multicolumn{1}{c}{ Sense (5'-3') } & \multicolumn{1}{c}{ Anti-sense (5'-3') } \\
\hline ORMDL3 & CCAACCUCAUUCACAACAUTT & AUGUUGUGAAUGAGGUUGGTT \\
SPHK1 & GAGGCUGAAAUCUCCUUCATT & UGAAGGAGAUUUCAGCCUCTT \\
GAPDH & UGACCUCAACUACAUGGUUTT & AACCAUGUAUUGAGGUCATT \\
\hline
\end{tabular}

Table II. Primers used in quantitative PCR for mouse lung assessment.

\begin{tabular}{lll}
\hline Gene & \multicolumn{1}{c}{ Forward primer (5'-3') } & \multicolumn{1}{c}{ Reverse primer (5'-3') } \\
\hline IL-4 & TCTCGAATGTACCAGGAGCCATAT & AAGCACCTTGGAAGCCCTACAGA \\
IL-13 & GCAGCATGGTATGGAGTGTG & CCTCTGGGTCCTGTAGATGG \\
TNF- $\alpha$ & CTGGATGTCAATCAACAATGGGA & ACTAGGGTGTGAGTGTTTTCTGT \\
Claudin-18 & GACCGTTCAGACCAGGTACA & GCGATGCACATCATCACTC \\
E-cadherin & CAGGCTGGCTGAAAGTGACA & ACGGATCCCTCAAACACCTC \\
SPHK1 & CATCACGGCCTGTAAAAAGGT & ATCTTCCACAAACCCAATCTGG \\
GAPDH & AATGGATTTGGACGCATTGGT & TTTGCACTGGTACGTGTTGAT \\
\hline
\end{tabular}

E, epithelial; SPHK1, sphingosine kinase 1; IL, interleukin; TNF, tumor necrosis factor.

for $72 \mathrm{~h}$ to yield a cell monolayer. Chemicals at proper concentrations were added to the inserts (TNF- $\alpha, 10 \mathrm{ng} / \mathrm{ml}$; DMS, $10 \mathrm{nM})$. Cells were serum-starved overnight before addition of TNF- $\alpha$ or DMS. TEER was monitored before (day 0 ) and at days 1 (24 h) to 5 daily with a Millicell-ERS2 Volt-Ohm Meter (EMD Millipore) according to the manufacturer's protocol. TEER was derived as $\left(R\right.$ sample- $R$ blank) $\mathrm{x}$ surface area $\left(\mathrm{cm}^{2}\right)$. The surface area was $0.33 \mathrm{~cm}^{2}$.

At day 5, epithelial permeability in ORMDL3/Vector and si-ORMDL3/si-control cells was measured by fluorescein isothiocyante (FITC)-conjugated dextran (4-kDa; $1 \mathrm{mg} / \mathrm{ml}$; Sigma-Aldrich; Merck KGaA) fluorescence strength. In this assay, 4-kDa-FITC-dextran was added to the apical side of the inserts while RPMI-1640 containing 2\% FBS was placed in lower wells. After $3 \mathrm{~h}, 100 \mu \mathrm{l}$ of fluid was collected from the basolateral compartment of each insert and transferred to 96-well plates (Corning, Inc.). Fluorescence was measured at $490 \mathrm{~nm}$, reflecting the amounts of fluoresce in sodium diffused from the apical side of the insert to the basal one. The values of FITC-dextran signals were normalized to the corresponding control groups (Vector or si-control) and presented as $\mathrm{Pa} / \mathrm{Pc} \%$.

SPHK1 activity assay. ORMDL3/Vector and si-ORMDL3/sicontrol cells were cultured in 24-well Transwell plates. At 5 days of culture, the cells were harvested and processed with SPHK1 Activity Assay kit I (Shanghai Haling Biotechnology Co., Ltd. http://www.halingbio.com). SPHK1 activity and percentage inhibition were calculated based on the manufacturer's protocol.

Western blot analysis. Western blot analysis was performed as described previously by the authors' team (15). The following antibodies were used and incubated overnight at $4^{\circ} \mathrm{C}$ : Anti-ORMDL3 (1:2,000; ab107639; Abcam),
anti-SPHK1 (1:1,000; ab71700; Abcam) and anti-Tubulin (1:2,000; ab179513; Abcam), anti-GAPDH (1:5,000; ab181602; Abcam), anti-Claudin-18 (1:2,000; 21126-1-AP; ProteinTech Group, Inc.), anti-E-cadherin (1:2,000; YT1454; ImmunoWay Biotechnology), anti-phospho-ERK1/2 (1:1,000; ab201015; Abcam; kindly provided by Dr Xiao-Fei, Jiang) and anti-ERK1/2 (1:1,000; ab17942; Abcam; kindly provided by Dr Xiao-Fei, Jiang). Goat anti-rabbit horseradish peroxidase-conjugated IgG (1:5,000; ab97051; Abcam) was used to detect antibody binding at room temperature for $2 \mathrm{~h}$. Target proteins were visualized using a ChemiDoc ${ }^{\mathrm{TM}}$ MP Imaging system (Bio-Rad Laboratories, Inc.) and analyzed using ImageLab software V5.1 (Bio-Rad Laboratories, Inc.).

$R N A$ extraction and $R T-q P C R$. Total RNA was isolated with TRIzol reagent according to the manufacturer's protocol (Takara Biotechnology, Co., Ltd.). cDNA was synthesized using the Prime Script ${ }^{\circledR}$ RT reagent kit with gDNA Eraser (Takara Biotechnology Co., Ltd.) according to the manufacturer's protocol. RT-qPCR was performed with cDNA samples using SYBR ${ }^{\circledR}$ Premix ExTapTMII (Takara Biotechnology Co., Ltd.). The primers are listed in Tables II and III. The reaction conditions were as follows: $30 \mathrm{sec}$ at $95^{\circ} \mathrm{C}$, followed by 40 cycles at $95^{\circ} \mathrm{C}$ for $5 \mathrm{sec}, 60^{\circ} \mathrm{C}$ for $30 \mathrm{sec}$ and $72^{\circ} \mathrm{C}$ for $30 \mathrm{sec}$. Relative changes in mRNA levels were measured by the $2^{-\Delta \Delta \mathrm{Cq}}$ method (29) and normalized to endogenous GAPDH.

Immunofluorescence (IF). IF staining of SPHK1, E-cadherin and Claudin-18 proteins in mouse lung samples, ORMDL3/Vector cells, and si-ORMDL3/si-control cells was performed. Cells were seeded on slides for $24 \mathrm{~h}$, fixed with $4 \%$ paraformaldehyde for $15 \mathrm{~min}$ at room temperature and washed 3 times with PBS. The samples were then blocked with goat serum (Gibco; Thermo Fisher Scientific, Inc.) in 
Table III. Primers used in quantitative PCR for cell assessment.

\begin{tabular}{lll}
\hline Gene & \multicolumn{1}{c}{ Forward primer $\left(5^{\prime}-3^{\prime}\right)$} & \multicolumn{1}{c}{ Reverse primer $\left(5^{\prime}-3^{\prime}\right)$} \\
\hline Claudin-18 & CCTGATGATCGTAGGCATCG & TGCATTTCAGGGCAAAGATG \\
E-cadherin & TCGTCACCACAAATCCAGTG & CATTCACATCAAGCACATCC \\
ORMDL3 & TCACCAACCTCATTCACAACAT & GACCCCATAATCCATATGCTC \\
SPHK1 & ATCACGGATGTATGACGTTTTGG & CAGGCTATTGCTGCGAAGAAC \\
GAPDH & TGTGGGCATCAATGGATTTGG & ACACCATGTATTCCGGGTCAAT
\end{tabular}

E, epithelial; SPHK1, sphingosine kinase 1; ORMDL3, orosomucoid-like protein isoform 3.

$5 \%$ bovine serum albumin/PBS for $1 \mathrm{~h}$ at room temperature and incubated with Alexa Fluor 647 (Abcam)-conjugated SPHK1, E-cadherin and Claudin-18, respectively, overnight at $4^{\circ} \mathrm{C}$. After two PBS washes, the cells were mounted with ProLong Gold containing DAPI (Life Technologies; Thermo Fisher Scientific, Inc.) and visualized under a Leica TCS SP5 confocal microscope (Leica Microsystems, Inc.).

Statistical analysis. Data are mean \pm standard deviation from six independent experiments with GraphPad Prism 6.0 (GraphPad Software, Inc.). Statistical analysis was performed with unpaired Student's t-test (for two experimental groups) or one-way analysis of variance (for multiple experimental groups), followed by Dunnett's post hoc test to determine the differences among multiple comparisons. $\mathrm{P}<0.05$ was considered to indicate a statistically significant difference.

\section{Results}

Successful establishment of a model of chronic asthma in mice by OVA-RSV induction. The authors' previous studies demonstrated that OVA-RSV induces mild airway inflammation in remittent asthmatic mice $(30,31)$. To ensure successful establishment of an animal model of chronic asthma, histopathological features were compared between the control and experimental groups. Consistent with the authors' previous findings (30), the amounts of inflammatory cells around the respiratory tract and vessels in the OVA-RSV group, as well as bronchial wall thickness, were significantly increased compared with control values $(\mathrm{P}<0.01$; Fig. 1B). PAS staining showed notable mucus secretion (Fig. 1C), while Masson's trichrome staining of lung sections from asthmatic mice revealed increased collagen deposition around the airway (Fig. 1D). Taken together, these findings indicated that the chronic asthmatic model was successfully established with OVA-RSV induction in mice.

OVA-RSV induction increases IL-4, IL-13 and TNF-a levels in serum and lung homogenates. High secretion levels of Th2 and pro-inflammatory cytokines is a well-established feature of asthma. To determine whether OVA-RSV treatment affects cytokine levels in serum, IL-4, IL-13 and TNF- $\alpha$ were detected by ELISA. Compared with the control values, serum IL-4, IL-13 and TNF- $\alpha$ levels were increased significantly by the OVA-RSV airway challenge $(\mathrm{P}<0.01$; Fig. $2 \mathrm{~A}-\mathrm{C})$. In addition, IL-4, IL-13 and TNF- $\alpha$ levels in lung homogenates were assessed by RT-qPCR and ELISA. Compared with the control group, the OVA-RSV group showed significantly increased expression levels of IL-4, IL-13 and TNF- $\alpha$, at the mRNA, and ELISA levels $(\mathrm{P}<0.01$; Fig. 2A-D). These findings indicated that OVA-RSV promoted allergic airway reactions by altering airway inflammation.

OVA-RSV induction increases ORMDL3 and SPHK1 expression levels in the mouse lung. Given that ORMDL3 is upregulated by OVA challenge (32), the effects of OVA-RSV on ORMDL3 expression were examined in vivo. OVA-RSV administration in mice resulted in significantly increased ORMDL3 protein levels in the lung tissue compared with control values (Fig. 2E).

It was reported that SPHK1 is involved in the pathological process of asthma (17). Meanwhile, a previous study revealed that ORMDL3 mediates sphingolipid metabolism in yeasts (33) and dysregulates ceramide homeostasis in A549 cells (18). SPHK1 represents a key enzyme in the regulation of sphingolipid metabolism and plays an essential role in plasma membrane formation $(8,15)$. Increased SPHK1 protein expression levels were observed by western blotting (Fig. 2F) in OVA-RSV stimulated mice vs. control animals. Furthermore, increased SPHK1 activity (Fig. 2G) and IF (Fig. 2H) density were found in the lung tissue of the model group compared with the control animals. These results implied that both ORMDL3 and SPHK1 were upregulated in OVA-RSV associated asthma in mice.

OVA-RSV induces loss of AE junction proteins in the lung tissue of asthmatic mice. Since asthmatic patients show dysfunctional AE barrier properties, whether OVA-RSV treatment affects the expression of epithelial junction proteins that maintain barrier integrity was examined. Claudin-18 and E-cadherin play important roles in maintaining the epithelial barrier integrity. Exposure to allergens or cytokines decreases E-cadherin expression in primary cells from asthmatic mice (34). Recent findings demonstrated that Claudin-18 expression is associated with the degree of lung injury (35). Consistent with previously reported data in allergen-exposed mice, OVA-RSV challenged mice exhibited loss of the AE junction molecule E-cadherin compared with control mice as shown by RT-qPCR (Fig. 3A) and western blotting (Fig. 3C), while OVA-RSV only decreased Claudin-18 mRNA expression (Fig. 3A) and not protein levels (Fig. 3B). To explore the detailed mechanisms behind ORMDL3's association with 
A

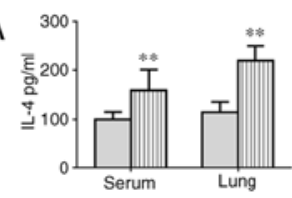

E ORMDL3

Tubulin
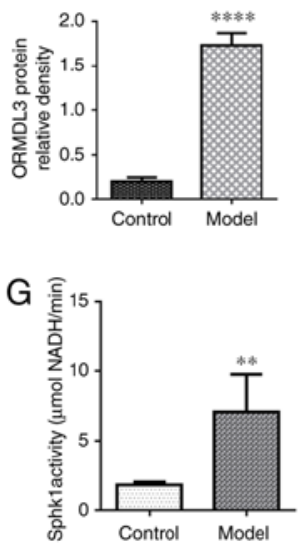

B

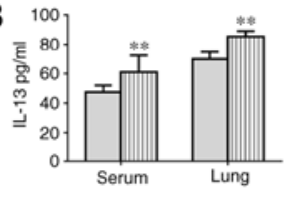

$\mathrm{F}$
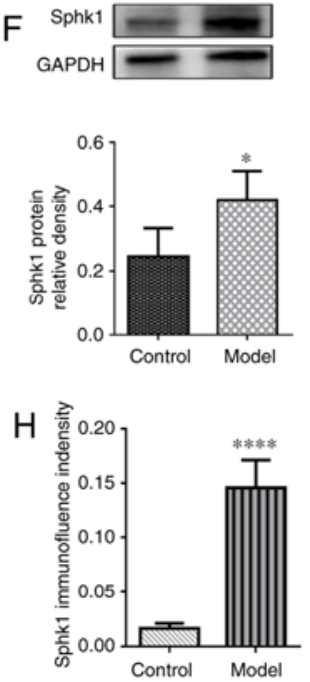

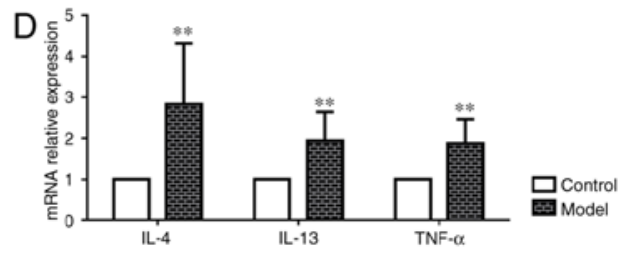

DAPI

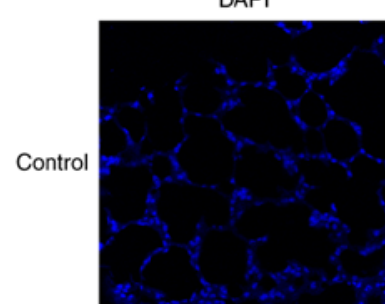

Sphk1

Merge

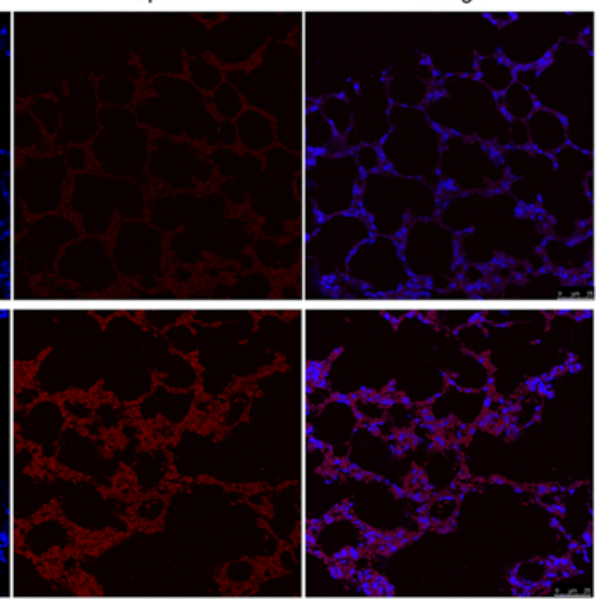

Figure 2. OVA-RSV upregulates pro-inflammatory cytokines, ORMDL3 and SPHK1 in asthmatic mice. (A-C) OVA-RSV treatment resulted in elevated (A) IL-4, (B) IL-13 and (C) TNF- $\alpha$ levels in asthmatic mouse serum and lung tissue samples. (D) OVA-RSV induced IL-4, IL-13 and TNF- $\alpha$ mRNA expression in the lung tissue of asthmatic mice. (E) ORMDL3 and (F) SPHK1 proteins were upregulated in the mouse lung of the OVA-RSV group. (G) SPHK1 activity was detected with SPHK1 Activity Assay kit I in the mouse lung tissue. (H) Immunofluorescent staining was used to assess the SPHK1 localization in the mouse lung tissue. Values are mean \pm standard deviation ( $\mathrm{n}=6$ per group). ${ }^{*} \mathrm{P}<0.05,{ }^{* *} \mathrm{P}<0.01$ and ${ }^{* * * * *} \mathrm{P}<0.001$ vs. the control group. $\mathrm{E}$, epithelial; SPHK1, sphingosine kinase 1; ORMDL3, orosomucoid-like protein isoform 3; si, small interfering; Ctrl, control; TNF, tumor necrosis factor; IL, interleukin; OVA-RSV, ovalbumin-respiratory syncytial virus.
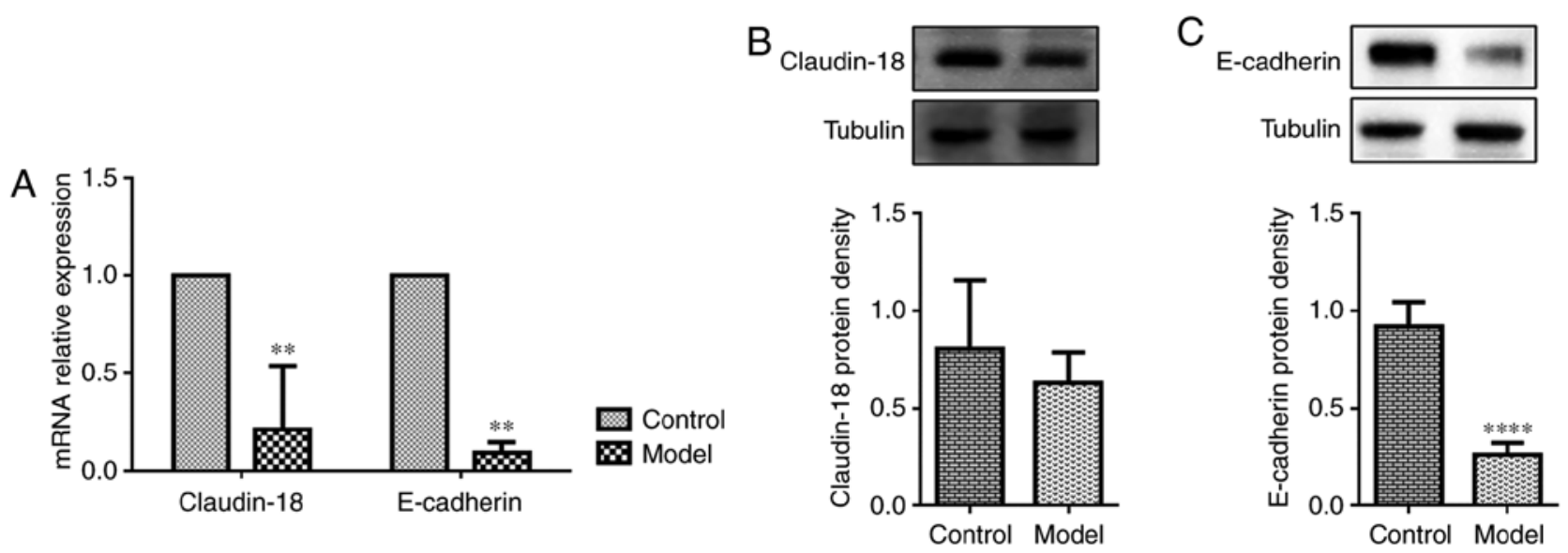

Figure 3. OVA-RSV induces loss of airway epithelium junction proteins in the lung tissue of asthmatic mice. (A) Gene expression levels of Claudin-18 and E-cadherin in lung homogenates. OVA-RSV mice showed reduced Claudin-18 and E-cadherin mRNA levels, consistent with (B) Claudin-18 and (C) E-cadherin protein amounts. Values are relative to Tubulin and were presented as mean \pm standard deviation $\left(\mathrm{n}=6\right.$ per group). ${ }^{* *} \mathrm{P}<0.01 \mathrm{vs}$. control group; ${ }^{* * * *} \mathrm{P}<0.0001$ vs. control group. E, epithelial; OVA-RSV, ovalbumin-respiratory syncytial virus.

airway barrier dysfunction, subsequent studies in 16HBE cells were performed since in vitro cell models allow the use of a large number of purified cells for molecular and biochemical analyses; in addition, using human cells could overcome species discrepancies which are common in experimental studies.

ORMDL3 overexpression decreases AE barrier integrity. To assess the effects of ORMDL3 on AE barrier integrity,
ORMDL3 in 16HBE cells was overexpressed or knocked down and the resulting cells were analyzed by RT-qPCR (Fig. 4A and B). TEER was measured at days 2-5 after ORMDL3/Vector or si-ORMDL3/si-control cells were seeded in Transwell plates. TEER was significantly decreased in cells overexpressing ORMDL3 compared with Vector transfected cells, while there was no difference between si-ORMDL3 and si-control cells $(\mathrm{P}<0.01$; Fig. $4 \mathrm{C}$ and $\mathrm{D})$. Epithelial membrane 

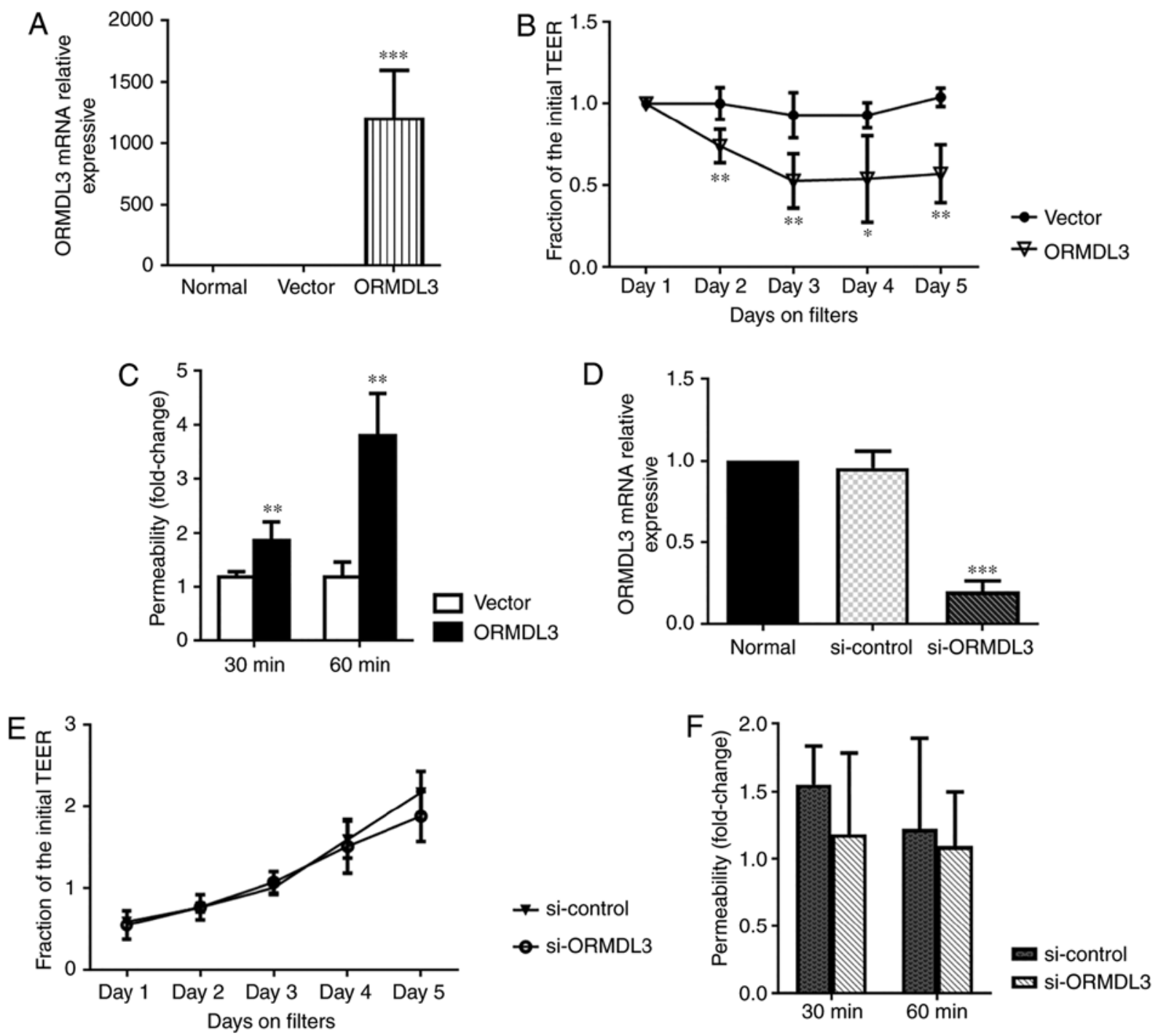

Figure 4. ORMDL3 overexpression impairs airway epithelium barrier integrity. ORMDL3 mRNA expression in (A) ORMDL3/Vector and (D) si-ORMDL3/si-control 16HBE cells showing successful overexpression and knockdown, respectively. After $24 \mathrm{~h}$ of culture, cells were collected, seeded in Transwell inserts and incubated for $72 \mathrm{~h}$ to form cell monolayers. (B) TEER of ORMDL3 in ORMDL3/Vector and (E) si-ORMDL3/si-control 16HBE monolayers were monitored at days 2 to 5. Epithelial permeability in (C) ORMDL3/Vector and (F) si-ORMDL3/si-control 16HBE cell monolayers were measured by treatment with 4-kDa FITC-dextran at day 5 . Values are mean \pm standard deviation ( $\mathrm{n}=6$ per group in duplicate). ${ }^{*} \mathrm{P}<0.05,{ }^{* * *} \mathrm{P}<0.01$ and ${ }^{* * *} \mathrm{P}<0.001$ vs. the corresponding control group. SPHK1, sphingosine kinase 1; ORMDL3, orosomucoid-like protein isoform 3; si, small interfering; Ctrl, control; TEER, transepithelial electrical resistance.

permeability assessment is an important method for evaluating AE barrier function. In the present study, epithelial permeability was measured by treatment with 4-kDa-FITC-dextran. As shown in Fig. 4E and F, ORMDL3 overexpression resulted in increased cell permeability compared with Vector transfected cells, while ORMDL3 knockdown did not affect cell permeability compared with the $s i$-ctrl group. These data suggested that ORMDL3 overexpression resulted in barrier function damage in $16 \mathrm{HBE}$ cells.

ORMDL3 overexpression downregulates Claudin-18 and E-cadherin. Whether ORMDL3 overexpression downregulates Claudin-18 and E-cadherin in 16HBE cells was assessed. The results showed that in $16 \mathrm{HBE}$ cells overexpressing ORMDL3, Claudin-18 and E-cadherin mRNA levels were roughly 50 and $70 \%$, respectively, compared with those of the controls (Fig. 5A), while ORMDL3 knockdown had opposite effects (Fig. 5B and D). However, only Claudin-18 protein expression was significantly decreased by ORMDL3 overexpression ( $\mathrm{P}<0.05$; Fig. 5C), while ORMDL3 knockdown had opposite effects (Fig. 5F). However, E-cadherin protein expression was not influenced by ORMDL3 (Fig. 5E and H). Moreover, IF data showed that ORMDL3 overexpression resulted in decreased Claudin-18 and E-cadherin fluorescence intensities (Fig. 5I). However, ORMDL3 knockdown did not influence Claudin-18 and E-cadherin fluorescence intensities and distribution (Fig. 5J). These data suggested that ORMDL3 overexpression induced bronchial epithelial barrier dysfunction by decreasing Claudin-18 protein levels, possibly disrupting the localization of Claudin-18 and E-cadherin in cell-cell contact.

ORMDL3 promotes SPHK1 activation and changes its distribution in 16HBE cells. To assess whether ORMDL3 induces 

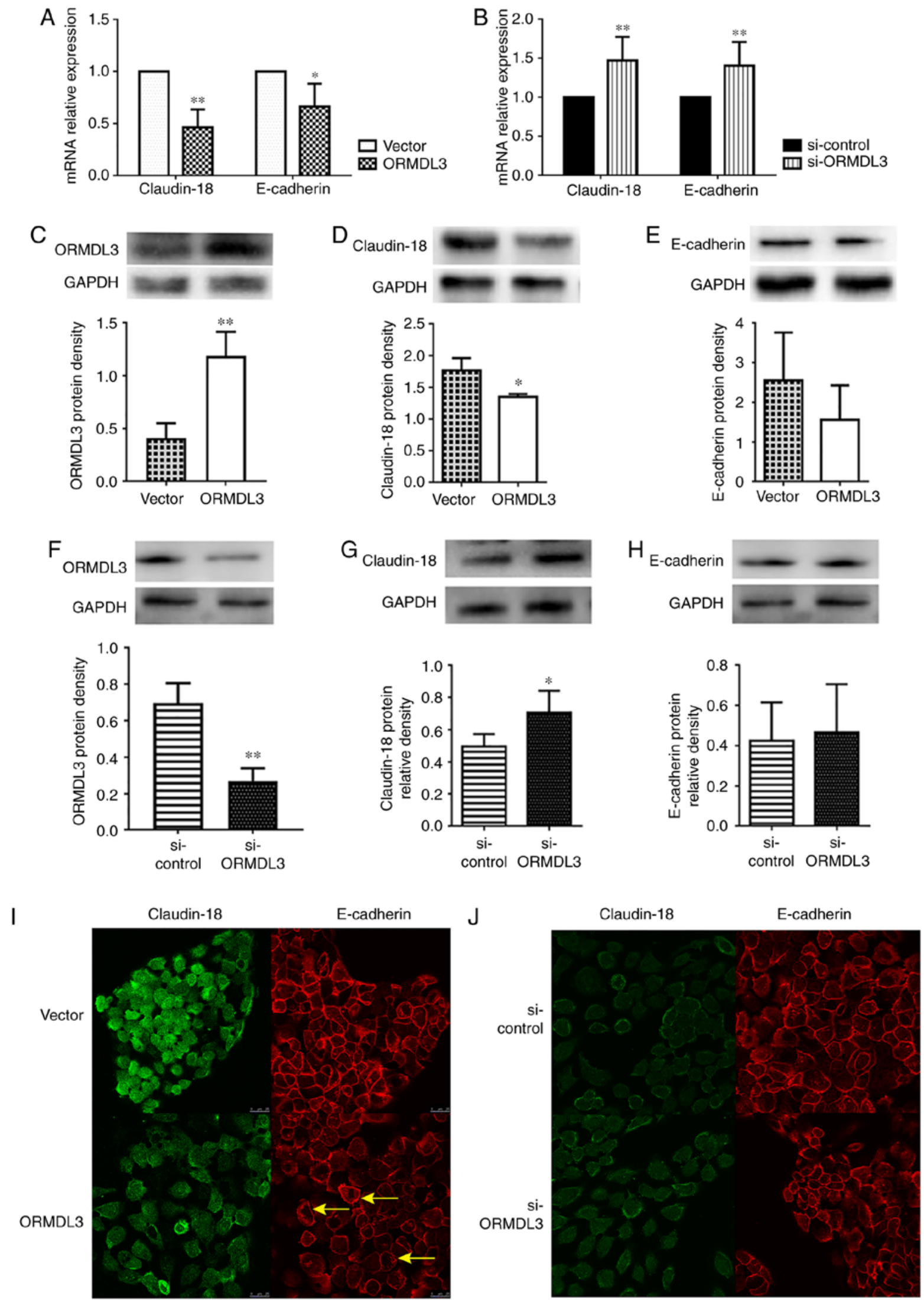

Figure 5. ORMDL3 overexpression downregulates TJ proteins. Assessment of Claudin-18 and E-cadherin mRNA expression levels in (A) ORMDL3/Vector and (B) si-ORMDL3/si-control 16HBE cells showing that ORMDL3 overexpression resulted in increased ORMDL3, reduced Claudin-18 and E-cadherin amounts, whereas ORMDL3 silencing led to reduced ORMDL3, elevated Claudin-18 and E-cadherin levels. The protein expression levels of (C) ORMDL3, (D) Claudin-18 and (E) E-cadherin in ORMDL3/Vector and the protein expression levels of (F) ORMDL3, (G) Claudin-18 and (H) E-cadherin in si-ORMDL3/si-control $16 \mathrm{HBE}$ cells were consistent with mRNA analysis. Immunofluorescence staining showing the localizations and signal intensities of Claudin-18 and E-cadherin in (I) ORMDL3/Vector and (J) si-ORMDL3/si-control $16 \mathrm{HBE}$ cells. Values are mean \pm standard deviation ( $\mathrm{n}=6$ per group in duplicate). ${ }^{*} \mathrm{P}<0.05$ and ${ }^{* * *} \mathrm{P}<0.01$ vs. the corresponding control group. Arrows show the stratification of TJs. E, epithelial; SPHK1, sphingosine kinase 1; ORMDL3, orosomucoid-like protein isoform 3; si, small interfering; Ctrl, control; TNF, tumor necrosis factor; ERK, extracellular signal regulated kinase; TJ, tight junction. 


\section{A Sphk1 \\ Tubulin}

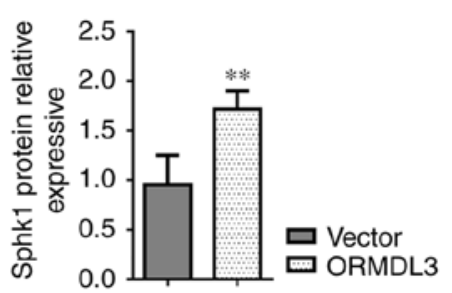

B

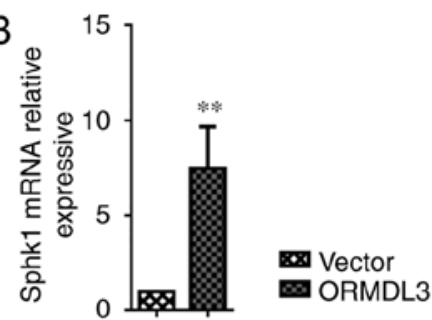

C

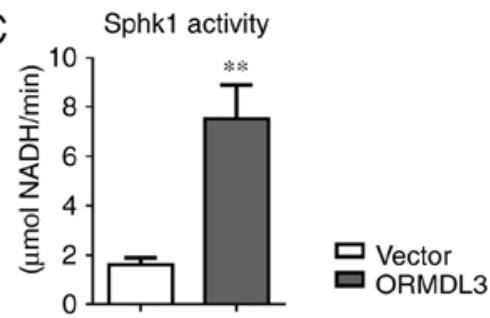

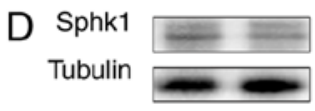
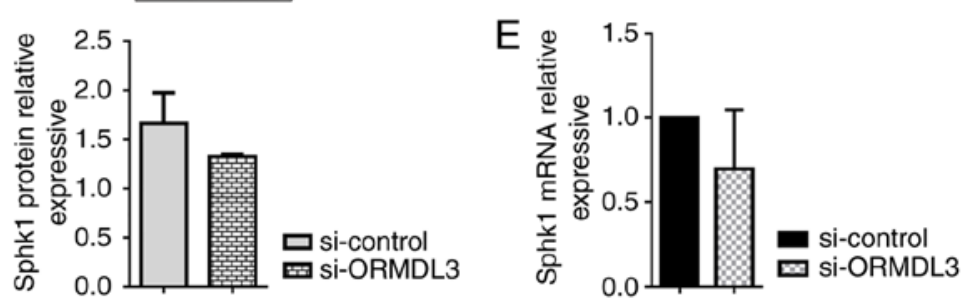

F

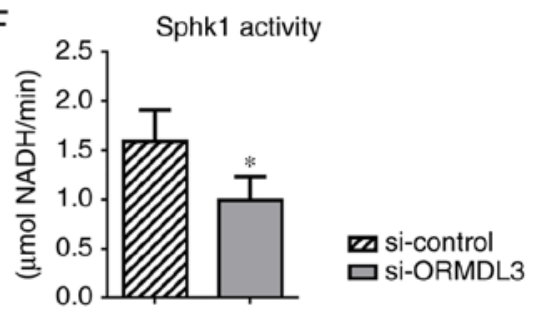

G

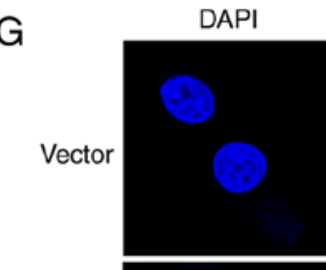

Sphk1

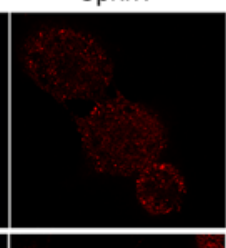

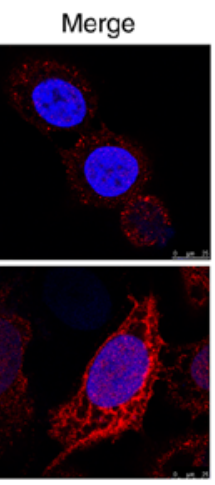

$\mathrm{H}$ DAPI

Sphk1

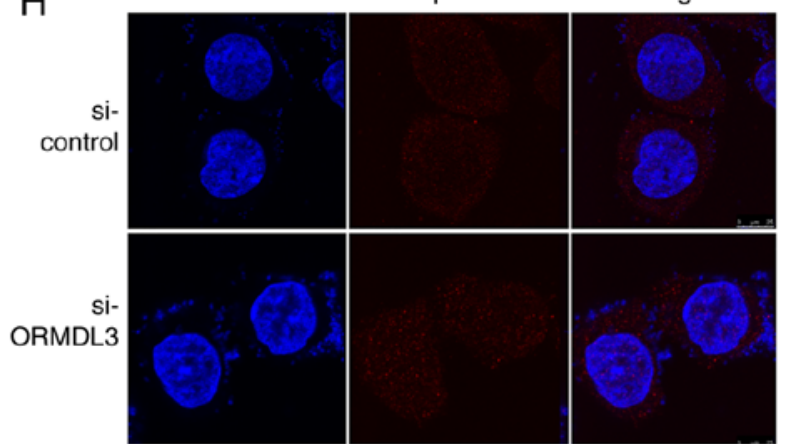

Figure 6. ORMDL3 promotes SPHK1 activation in 16HBE cells. SPHK1 protein expression levels in (A) ORMDL3/Vector and (B) si-ORMDL3/si-control 16HBE cells, detected by western blotting. SPHK1 mRNA expression levels in (C) ORMDL3/Vector and (D) si-ORMDL3/si-control 16HBE cells, detected by quantitative PCR. Enzyme activities of SPHK1in (E) ORMDL3/Vector and (F) si-ORMDL3/si-control 16HBE cells, detected with SPHK1 Activity Assay kit I. Immunofluorescence staining was used to assess SPHK1 localization in $(\mathrm{G})$ ORMDL3/Vector and (H) si-ORMDL3/si-control 16HBE cells. Values are the mean \pm standard deviation $\left(\mathrm{n}=6\right.$ per group in duplicate). ${ }^{*} \mathrm{P}<0.05$ and ${ }^{* *} \mathrm{P}<0.01$ vs. the corresponding control group. SPHK1, sphingosine kinase 1; ORMDL3, orosomucoid-like protein isoform 3; si, small interfering; Ctrl, control.

changes in plasma membrane composition, SPHK1 activity was determined and distribution in ORMDL3 overexpressing and silenced $16 \mathrm{HBE}$ cells, respectively. Consistent with the findings in OVA-RSV mice, SPHK1 expression in 16HBE cells showed altered patterns in response to ORMDL3 overexpression, with mRNA and protein expression levels significantly increased in 16HBE ORMDL3 overexpressing cell monolayers $(\mathrm{P}<0.01$; Fig. 6A and B). Meanwhile, the opposite effects were observed after ORMDL3 knockdown although there were no statistically significant differences (Fig. 6C and D). To evaluate whether SPHK1 is activated more after upregulation, SPHK1 activities in ORMDL3 overexpressing and silenced cells were assessed, respectively. ORMDL3 overexpressing cells displayed increased SPHK1 activity compared with the Vector group (Fig. 6E) and ORMDL3 silencing resulted in significantly decreased SPHK1 activity compared with si-ctrl cells $(\mathrm{P}<0.05$; Fig. 6F). Moreover, cellular localization of SPHK1 was assessed in ORMDL3/Vector and si-ORMDL3/si-control cells. The results showed that different from the cytoplasmic localization of SPHK1 in Vector and si-ctrl cells, ORMDL3 overexpression resulted in SPHK1 localizing to the plasma membrane, thereby indicating SPHK1 activation (Fig. 6G); ORMDL3 suppression caused no change of SPHK1 localization (Fig. 6H). These data indicated that ORMDL3 overexpression resulted in SPHK1 relocation and activation.

SPHK1 silencing alleviates AE dysfunction induced by ORMDL3 overexpression. TNF- $\alpha$ is a powerful epithelial barrier $(23,36,37)$, damage inducer and has been confirmed as a SPHK1 agonist. Moreover, a recent study found TNF- $\alpha$ increases ORMDL3 protein expression in 293 cells (38). The cell viability assay (Fig. S1) shows that $10 \mathrm{ng} / \mathrm{ml} \mathrm{TNF-} \alpha$ is the most suitable concentrate for $16 \mathrm{HEB}$ cells. TNF- $\alpha(10 \mathrm{ng} / \mathrm{ml})$ was used in the following assays to investigate whether inhibiting SPHK1 by si-RNA could rescue the phenotypes associated with TNF- $\alpha$, similar to ORMDL3 overexpression. To evaluate the relationship between ORMDL3 and SPHK1, was first transfected with $s i-S P H K 1$ in normal $16 \mathrm{HBE}$ cells 

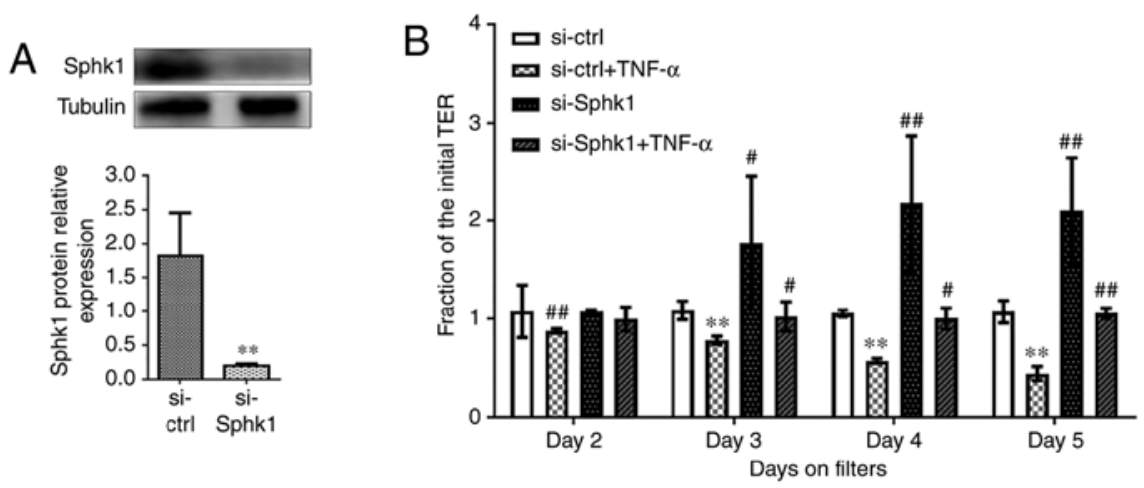

C

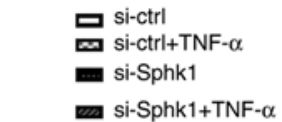

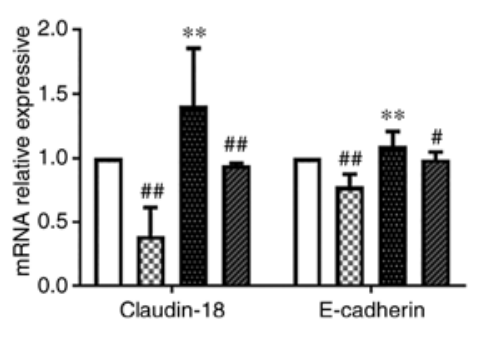

D

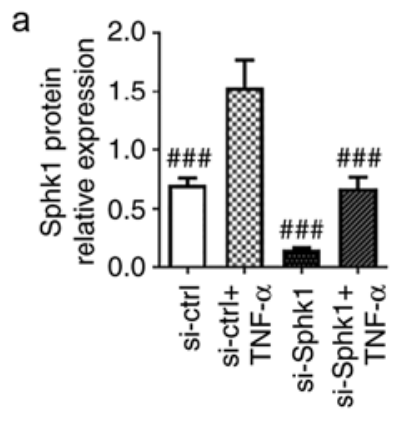

C

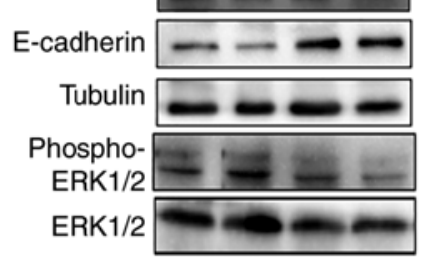

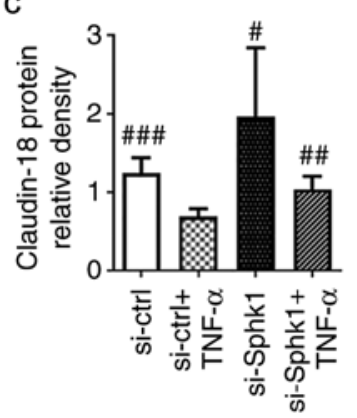

d

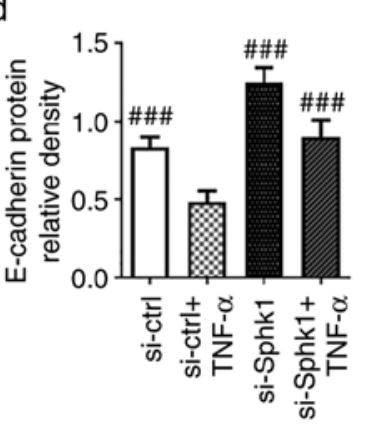

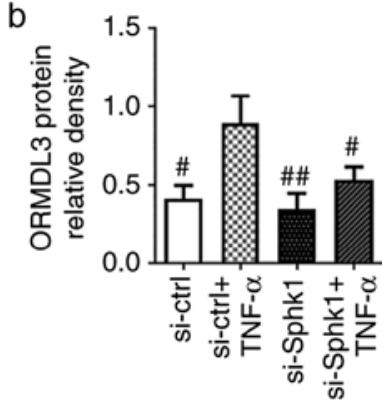

e

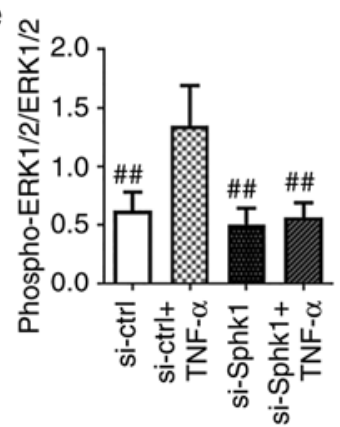

Figure 7. SPHK1 silencing alleviates ORMDL3 induced airway barrier dysfunction. (A) SPHK1 protein expression in si-SPHK1/si-ctrl 16HBE cells was detected by western blotting. (B) $s i$-SPHK1/si-ctrl cells were treated with TNF- $\alpha(10 \mathrm{ng} / \mathrm{ml})$ for 5 days and TEER was measured daily. (C) Claudin- 18 and E-cadherin mRNA expression levels in si-SPHK1/si-ctrl and si-SPHK1+TNF- $\alpha /$ si-ctrl+TNF- $\alpha$ cells were detected by qRT-PCR. (D-a) Sphk1, (b) ORMDL3, (c) Claudin-18, (d) E-cadherin and (e) ERK1/2 protein expression levels in si-SPHK1/si-ctrl and si-SPHK1+TNF- $\alpha / s i$-ctrl+TNF- $\alpha$ cells were detected by western blotting.

for $48 \mathrm{~h}$ before treatment with TNF- $\alpha$ for another 5 days. The knockdown efficiency of $s i$-SPHK1 was determined by western blotting. As shown in Fig. 7A, SPHK1 protein levels in cells transfected with $s i$-SPHK1 were only $5 \%$ of those found in cells transfected with si-ctrl. It was found that reduced TEER in $16 \mathrm{HBE}$ cell monolayers due to TNF- $\alpha$ treatment could be largely prevented by SPHK1 knockdown (Fig. 7B). The mRNA and protein levels of Claudin-18 and E-cadherin were significantly increased in the si-SPHKl and si-SPHK1+TNF- $\alpha$ groups compared with the $s i-c t r l+T N F-\alpha$ group $(\mathrm{P}<0.01$; Fig. 7C and D, panels $\mathrm{c}$ and $\mathrm{d}$ ). These results indicated a negative correlation between SPHK1 and ORMDL3 proteins (Fig. 7D, panels a and b). Since SPHK1 induces ERK1/2 transactivation $(31,39)$, ERK phosphorylation was evaluated and it was found that SPHK1 knockdown alleviated TNF- $\alpha$ induced ERK phosphorylation (Fig. 7D, panel e).

To further assess the role of SPHK1 in ORMDL3 induced airway barrier dysfunction, ORMDL3 overexpressing cells were treated with the specific SPHK1 inhibitor DMS (10 nM) for 5 days. The results showed that DMS restored TEER decrease associated with ORMDL3 overexpression (Fig. 7E).
ORMDL3 overexpression induced SPHK1 and ORMDL3 protein expression, but this was decreased by SPHK1 inhibitor (Fig. 7G, panels a and b). RT-qPCR and western blotting demonstrated that ORMDL3 overexpression induced SPHK1 protein expression, and decreased Claudin-18 and E-cadherin levels; these effects were restored by the above SPHK1 inhibitor (Fig. 7F and G, panels c and d). Furthermore, ORMDL3 overexpression induced robust ERK1/2 phosphorylation and was partly blocked by DMS (Fig. 7G, panel e). Collectively, these data demonstrated that SPHK1/ERK1/2 signaling may be downstream of ORMDL3 in promoting bronchial epithelial barrier dysfunction.

\section{Discussion}

Asthma is considered a heterogeneous disorder resulting from a complex interplay between genetic susceptibility, allergenic triggers and viral infection. Substantial efforts have been directed toward its management. Rational therapy of chronic asthma is important for maintaining the asthmatic patient's daily life. However, current studies mainly focus on acute or 
E

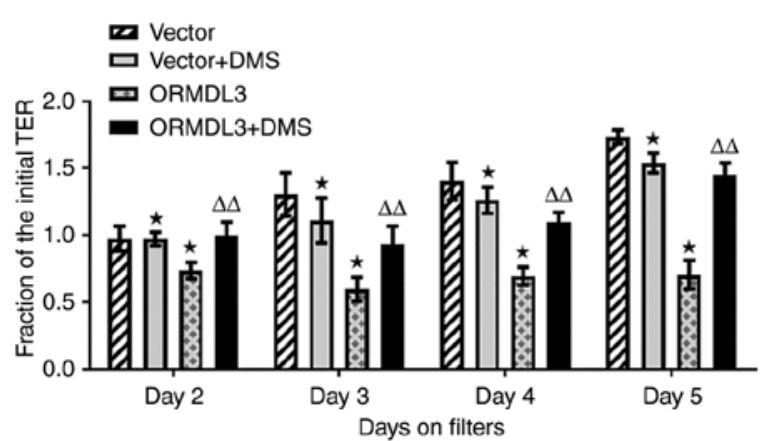

$\mathrm{F}$

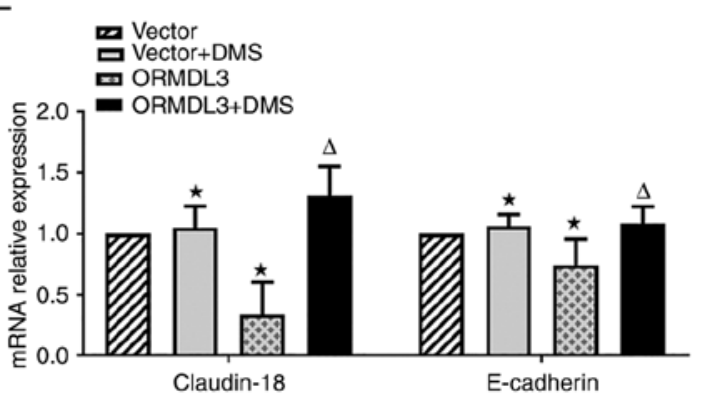

G

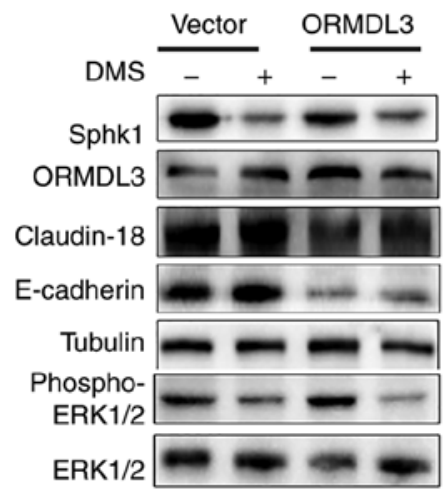

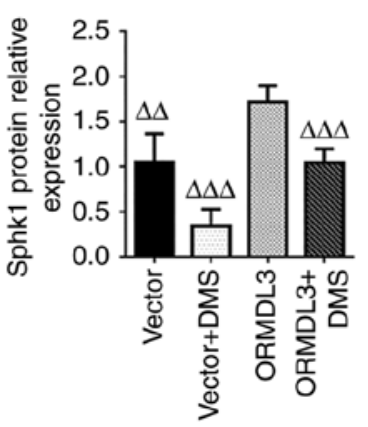

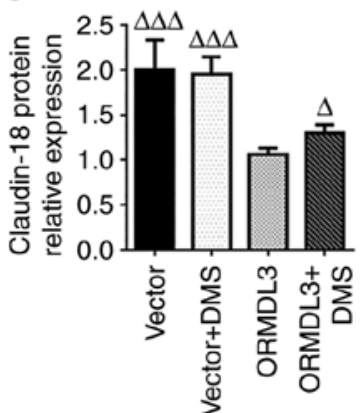

d
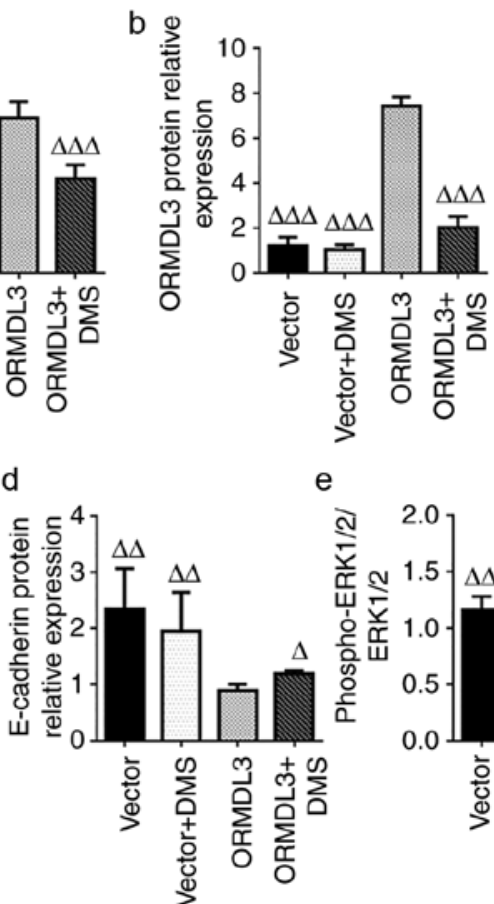

e

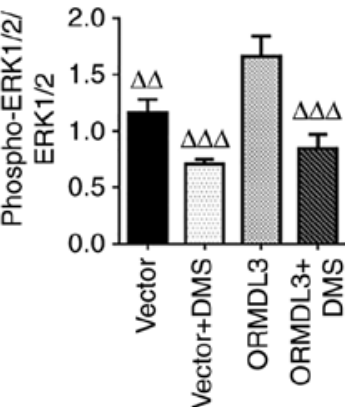

Figure 7. Continued. (E) ORMDL3/Vector cells were treated with DMS (10 nM) for 5 days and TEER was measured daily. (F) Claudin-18 and E-cadherin mRNA expression levels in ORMDL3/Vector and ORMDL3+DMS/Vector+DMS cells were detected by qRT-PCR. (G-a) Sphk1, (b) ORMDL3, (c) Claudin-18, (d) E-cadherin and (e) ERK1/2 protein expression levels in ORMDL3+DMS/Vector $+D M S$ cells were detected by western blotting. Data are presented as the mean \pm standard deviation of six independent experiments. ${ }^{* *} \mathrm{P}<0.01$ vs. si-ctrl group. ${ }^{\#} \mathrm{P}<0.05,{ }^{\# \#} \mathrm{P}<0.01$ and ${ }^{\# \# \#} \mathrm{P}<0.001$ vs. si-ctrl $+T N F$ - $a$ group. ${ }^{\star} \mathrm{P}<0.05$ vs. the Vector group. ${ }^{\Delta} \mathrm{P}<0.05,{ }^{\Delta \Delta} \mathrm{P}<0.01$ and ${ }^{\Delta \Delta \Delta} \mathrm{P}<0.001$ vs. ORMDL3 group. E, epithelial; SPHK1, sphingosine kinase 1; ORMDL3, orosomucoid-like protein isoform 3; si, small interfering; ctrl, control; TNF, tumor necrosis factor; ERK, extracellular signal regulated kinase.

severe asthma rather than chronic disease. Thus, it is urgent to develop proper animal models to investigate the potential molecular mechanisms of chronic asthma.

Challenge allergens, methods, times and periods vary in different studies. OVA is a conventional allergen used in asthmatic animal studies; it induces airway inflammation in mice but does not affect most structural changes associated with chronic asthma. Airway infection always induces asthmatic attack. As the most common respiratory pathogen in childhood, RSV is a cause of morbidity and mortality in elderly and high-risk adults (40). RSV infection alters the lung microenvironment, impairs tolerance to inhaled allergens and increases the patient's susceptibility to asthma (41). Emerging evidence points out that RSV contributes to AE barrier disruption via AJC disassembly and increased paracellular permeability (42). A short-term study compared airway hyperresponsiveness and pathological changes of the lung tissue in RSV infected mice, OVA challenged mice, and OVA-sensitized and RSV infected (OVA/RSV) mice. The results indicated RSV infection during
OVA sensitization prolongs AHR and increases lung lymphocyte amounts as well as airway mucus production (43). To the best of our knowledge, no studies have combined viral infection with allergen challenge in long-term asthmatic animal models. In a previous study, it was demonstrated that OVA-RSV significantly increases inflammation scores, goblet cell hyperplasia and collagen deposition following the last RSV infection (56 days). A total of 30 days after the last infection, respiratory mucus hypersecretion and airway remodeling were absent, but airway inflammation was still observed (30). In the present study, the chronic asthmatic mouse model was modified and the expected characteristics were obtained, including airway inflammation and remodeling, with no mucus hypersecretion. These findings indicate that chronic changes associated with the characteristic features of inflammation and remodeling have been generated successfully in the present animal model.

In the pathogenesis of asthma, inflammatory cells initiate and maintain key pathological features through production of cytokines (42). In preliminary experiments, increased CXCL1, 
CXCL2 and CCL11 levels in serum, elevated interferon- $\gamma$ amounts in the lung tissue, and significantly increased IL-6 and TGF- $\beta$ levels in the bronchoalveolar lavage fluid 30 days after the last OVA-RSV challenge were observed $(23,31)$. In the present study, the levels of cytokines in the modified chronic model of murine allergic asthma induced by OVA-RSV were evaluated and higher serum and lung tissue IL-4, IL-13 and TNF- $\alpha$ amounts were found. Previous studies have indicated that the above three cytokines affect TJs in vivo and in vitro $(23,44-46)$. In addition, administration of IL-4, IL-13 and TNF- $\alpha$ significantly induces ORMDL3 expression $(9,38)$. These findings prompted the present study to investigate the relationship between ORMDL3 expression and bronchial epithelial barrier dysfunction. Previous data have suggested that ORMDL3 plays a role in airway remodeling (including increased airway smooth muscle, sub-epithelial fibrosis and mucus formation), airway responsiveness, and lung elasticity $(47,48)$; however, its effects on AE cells are not well understood. The results of the present study indicated that OVA-RSV challenge increased ORMDL3 expression in the lung tissue of chronic asthmatic mice.

Bronchial epithelial cells play an important role in asthma pathology. Increased permeability to external substances, reduced TEER and disruption of junctional proteins are used to assess epithelial barrier dysfunction. Hyperpermeability of bronchial epithelial cells results in greater penetration of inhaled allergens and particles into the sub-epithelial space, facilitating antigen sampling and inducing innate and adaptive immune responses (49). Junctional proteins are important for initiating and maintaining cell-cell adhersion, and participate in numerous signal transduction cascades. E-cadherin is important in maintaining tissue morphogenesis and polarity, and necessary for adhesion junction formation $(50,51)$. Claudin-18.1 is localized at TJs and represents the only known lung-specific tight junction gene product (52-54). Claudin-18 levels are decreased in subjects with asthma and Claudin-18-deficient mice show exacerbated serum IgE increase and enhanced airway hyperresponsiveness following intranasal antigen sensitization (55). Meanwhile, decreased Claudin-18 and E-cadherin protein levels in epithelial cells contribute to defective AE barrier in patients with atopic asthma $(35,56)$. It was demonstrated that OVA-RSV decreased Claudin-18 and E-cadherin mRNA levels, with no effect on Claudin-18 protein expression in the lung tissue of mouse models. To further assess the role of ORMDL3 in bronchial epithelial barrier dysfunction, ORMDL3 expression was manipulated in $16 \mathrm{HBE}$ cells. The results suggested that ORMDL3 overexpression significantly increased TEER, decreased permeability, downregulated Claudin-18 at the mRNA and protein levels, and altered E-cadherin distribution in 16HBE cells, while si-RNA-mediated ORMDL3 silencing had opposite effects. This implied that ORMDL3 overexpression could impair bronchial epithelial barrier function.

The cell membrane component sphingolipid has attracted substantial attention in recent years. Several studies have established its role in cell growth, survival and migration (15-17). ORMDL3 is involved in sphingolipid metabolism and de novo sphingolipid synthesis (9). An In vitro study revealed ORMDL3 overexpression at mid-levels inhibits SPT activity; however, more pronounced ORMDL3 overexpression results in increased sphingolipid levels (18). SPHK1 is a key lipid kinase involved in the regulation of sphingolipid metabolism. Interestingly, SPHK1 mRNA levels are significantly increased in airway diseases (19-21). Previous studies have proposed that SPHK1 is associated with airway inflammation, goblet cell hyperplasia, and hyperresponsiveness $(19,22,23)$. The possible mechanisms include calcium flux control, arachidonic acid release, and induced ERK phosphorylation (24-26). In vivo studies have demonstrated that treatment with a SPHK1 inhibitor or SPHK1 knockout ameliorates OVA-induced AHR and airway inflammation in mice $(22,26)$. The present findings indicated that OVA-RSV challenge could boost SPHK1 activity in the lung tissue of asthmatic mice, and SPHK1 levels paralleled those of ORMDL3.

IF revealed SPHK1 distribution in the cytoplasmic compartment of normal 16HBE cells, whereas ORMDL 3 overexpression caused SPHK1 to translocate to the cell membrane; however, ORMDL3 knockdown did not affect SPHK1 location. A study of head and neck carcinoma indicated that SPHK1 expression correlates with E-cadherin downregulation (15). To investigate whether SPHK1 is involved in ORMDL3 induced airway barrier dysfunction, ORMDL3 overexpressing cells were treated with DMS, which resulted in decreased ORMDL3 levels in these cells, although not reaching the normal levels. Meanwhile, DMS alleviated TEER and junctional protein expression changes associated with ORMDL3 overexpression. These results demonstrated that SPHK1 is involved in ORMDL3 induced bronchial epithelial barrier dysfunction as a downstream effector.

The mitogen-activated protein kinase (MAPK) family is a group of serine/threonine kinases, which include p38 MAPK and ERK protein kinase pathways. Increasing evidence indicates that activation of the MAPK/ERK pathway promotes the proliferation, migration and differentiation of peripheral cells around airway epithelial damage $(57,58)$. Impaired alveolar barrier function in septic rats is associated with ERK-mediated downregulation of several tight junction components (59). Furthermore, the ERK pathway is implicated in barrier function dysregulation attributed to reduced levels of junctional proteins in AE cells (60). Previous studies reported that the SPHK1/ERK1/2 signaling pathway is involved in mucus production in human AE cells. In the present study, the effects of ORMDL 3 on the ERK1/2 signaling cascade were assessed $(19,24,61)$. The results showed that the SPHK1 inhibitor DMS alleviated AE barrier dysfunction and ERK signaling pathway activation associated with ORMDL3 overexpression.

However, there were certain limitations in this study. AHR and de novo sphingolipid metabolism were not evaluated in the current mouse model, which requires further assessment using ORMDL3 transgenic mice.

In conclusion, this study provided novel findings that ORMDL3 overexpression results in damaged epithelial barrier integrity, reflected by higher epithelial permeability, increased inflammatory cytokine secretion, decreased TEER and hampered expression of AE molecules. In long-term chronic asthma mouse models, induced ORMDL3overexpression was observed alongside Claudin-18 and E-cadherin downregulation. The in vitro study suggested that ORMDL3 overexpression promotes ERK1/2 phosphorylation, and via SPHK1 activation and inhibition, reverses ORMDL3 induced 
AE barrier dysfunction by alleviating ERK1/2 phosphorylation. Taken together, these findings reveal a novel role for ORMDL3 in the pathogenesis of asthma.

\section{Acknowledgements}

The authors would like to thank Dr Xiaofei Jiang from Jiangsu Key Laboratory of Pediatric Respiratory Disease for providing the anti-phospho-ERK1/2 and anti-ERK1/2 antibodies.

\section{Funding}

The present study was partly supported by grants from the the National Natural Science Foundation of China, China (grant no. 81473723) and the Innovation Program for Graduate Students of Jiangsu Province, China (grant no. KYZZ17_1316).

\section{Availability of data and materials}

The authors declare that all supporting data are available within the article and its online supplementary files.

\section{Authors' contributions}

RY and MT performed the experiments. RY, MT and JX analyzed and interpreted the data. XZ made substantial contributions to the design supervision of the present study. RY wrote the manuscript. All authors reviewed the results and approved the final version of the manuscript.

\section{Ethics approval and consent to participate}

All animal experiments were performed according to procedures approved by the Animal Ethics Committee of Nanjing University of Chinese Medicine.

\section{Patient consent for publication}

Not applicable.

\section{Compenting interests}

All authors declare that they have no any conflict of interests.

\section{References}

1. Global Initiative for Asthma: Global strategy for asthma management and prevention, 2017.

2. Martinez FD and Vercelli D: Asthma. Lancet 382: 1360-1372, 2013

3. McGarvey LP, Butler CA, Stokesberry S, Polley L, McQuaid S, Abdullah H, Ashraf S, McGahon MK, Curtis TM, Arron J, et al: Increased expression of bronchial epithelial transient receptor potential vanilloid 1 channels in patients with severe asthma. J Allergy Clin Immunol 133: 704-712.e4, 2014.

4. Hackett TL and Knight DA: The role of epithelial injury and repair in the origins of asthma. Curr Opin Allergy Clin Immunol 7: 63-68, 2007.

5. Chung KF: Intrinsic differences of the airway epithelium in childhood allergic asthma. Am J Respir Crit Care Med 174 1066-1067, 2006.

6. Xiao C, Puddicombe SM, Field S, Hay wood J, Broughton-Head V, Puxeddu I, Haitchi HM, Vernon-Wilson E, Sammut D, Bedke N, et al: Defective epithelial barrier function in asthma. J Allergy Clin Immunol 128: 549-556.e1-e12, 2011.
7. Kicic A, Sutanto EN, Stevens PT, Knight DA and Stick SM: Intrinsic biochemical and functional differences in bronchial epithelial cells of children with asthma. Am J Respir Crit Care Med 174: 1110-1118, 2006.

8. Moffatt MF: Genes in asthma: New genes and new ways. Curr Opin Allergy Clin Immunol 8: 411-417, 2008.

9. MillerM,Rosenthal P,Beppu A,MuellerJL,Hoffman HM,Tam AB, Doherty TA, McGeough MD, Pena CA, Suzukawa M, et al: ORMDL3 transgenic mice have increased airway remodeling and airway responsiveness characteristic of asthma. J Immunol 192: 3475-3487, 2014

10. Hjelmqvist L, Tuson M, Marfany G, Herrero E, Balcells S and Gonzàlez-Duarte R: ORMDL proteins are a conserved new family of endoplasmic reticulum membrane proteins. Genome Biol 3: RESEARCH0027, 2002.

11. Miller M, Tam AB, Cho JY, Doherty TA, Pham A, Khorram N, Rosenthal P, Mueller JL, Hoffman HM, Suzukawa M, et al: ORMDL3 is an inducible lung epithelial gene regulating metalloproteases, chemokines, OAS, and ATF6. Proc Natl Acad Sci USA 109: 16648-16653, 2012.

12. Carreras-Sureda A, Cantero-Recasens G, Rubio-Moscardo F, Kiefer K, Peinelt C, Niemeyer BA, Valverde MA and Vicente R: ORMDL3 modulates store-operated calcium entry and lymphocyte activation. Hum Mol Genet 22: 519-530, 2013.

13. Worgall TS, Veerappan A, Sung B, Kim BI, Weiner E, Bholah R, Silver RB, Jiang XC and Worgall S: Impaired sphingolipid synthesis in the respiratory tract induces airway hyperreactivity. Sci Transl Med 5: 186ra67, 2013.

14. Levy BD: Sphingolipids and susceptibility to asthma. N Engl J Med 369: 976-978, 2013.

15. Young MM, Kester M and Wang HG: Sphingolipids: Regulators of crosstalk between apoptosis and autophagy. J Lipid Res 54: 5-19, 2013.

16. Schiefler C, Piontek G, Doescher J, Schuettler D, Mißlbeck M, Rudelius M, Haug A, Reiter R, Brockhoff G and Pickhard A: Inhibition of SphK1 reduces radiation-induced migration and enhances sensitivity to cetuximab treatment by affecting the EGFR/SphK1 crosstalk. Oncotarget 5: 9877-9888, 2014.

17. Tamashiro PM, Furuya H, Shimizu Y and Kawamori T: Sphingosine kinase 1 mediates head \& neck squamous cell carcinoma invasion through sphingosine 1-phosphate receptor 1. Cancer Cell Int 14: 76, 2014.

18. Oyeniran C, Sturgill JL,Hait NC, Huang WC, Avni D, Maceyka M, Newton J, Allegood JC, Montpetit A, Conrad DH, et al: Aberrant ORM (yeast)-like protein isoform 3 (ORMDL3) expression dysregulates ceramide homeostasis in cells and ceramide exacerbates allergic asthma in mice. J Allergy Clin Immunol 136: 1035-1046.e6, 2015.

19. Natarajan V,Ha AW, Dong Y, Reddy NM, Ebenezer DL, Kanteti P, Reddy SP, Usha Raj J, Lei Z, Maienschein-Cline M, et al: Expression profiling of genes regulated by sphingosine kinasel signaling in a murine model of hyperoxia induced neonatal bronchopulmonary dysplasia. BMC Genomics 18: 664, 2017.

20. Nishiuma T, Nishimura Y, Okada T, Kuramoto E, Kotani Y, Jahangeer $S$ and Nakamura $S$ : Inhalation of sphingosine kinase inhibitor attenuates airway inflammation in asthmatic mouse model. Am J Physiol Lung Cell Mol Physiol 294: L1085-L1093, 2008.

21. Xu CY, Liu SQ, Qin MB, Zhuge CF, Qin L, Qin N, Lai MY and Huang JA: SphK1 modulates cell migration and EMT-related marker expression by regulating the expression of p-FAK in colorectal cancer cells. Int J Mol Med 39: 1277-1284, 2017.

22. Haberberger RV, Tabeling C, Runciman S, Gutbier B, König P, Andratsch M, Schütte H, Suttorp N, Gibbins I and Witzenrath M: Role of sphingosine kinase 1 in allergen-induced pulmonary vascular remodeling and hyperresponsiveness. J Allergy Clin Immunol 124: 933-941.e1-e9, 2009.

23. Sim TY, Harith HH, Tham CL, Md Hashim NF, Shaari K, Sulaiman MR and Israf DA: The protective effects of a synthetic geranyl acetophenone in a cellular model of TNF- $\alpha$-induced pulmonary epithelial barrier dysfunction. Molecules 23: pii: E1355, 2018.

24. Kono Y, Nishiuma T, Okada T, Kobayashi K, Funada Y, Kotani Y, Jahangeer S, Nakamura S and Nishimura Y: Sphingosine kinase 1 regulates mucin production via ERK phosphorylation. Pulm Pharmacol Ther 23: 36-42, 2010.

25. Oskeritzian CA, Alvarez SE, Hait NC, Price MM, Milstien S and Spiegel S: Distinct roles of sphingosine kinases 1 and 2 in human mast-cell functions. Blood 111: 4193-4200, 2008. 
26. Price MM, Oskeritzian CA, Falanga YT, Harikumar KB, Allegood JC, Alvarez SE, Conrad D, Ryan JJ, Milstien S and Spiegel S: A specific sphingosine kinase 1 inhibitor attenuates airway hyperresponsiveness and inflammation in a mast cell-dependent murine model of allergic asthma. J Allergy Clin Immunol 131: 501-511.e1, 2013.

27. Huang Z, Gao L, Zhao X, Ling $H$ and Chen W: Effect of Gubenfangxiao decoction on respiratory syncytial virus-induced asthma and expression of asthma susceptibility gene orosomucoid 1-like protein 3 in mice. J Tradit Chin Med 36: 101-106, 2016

28. Page K, Lierl KM, Herman N and Wills-Karp M: Differences in susceptibility to German cockroach frass and its associated proteases in induced allergic inflammation in mice. Respir Res 8: 91, 2007.

29. Livak KJ and Schmittgen TD: Analysis of relative gene expression data using real-time quantitative PCR and the 2(-Delta Delta C(T)) method. Methods 25: 402-408, 2001.

30. Lu Y, Xu JY, Zhang XH and Zhao X: Gu-Ben-Fang-Xiao decoction attenuates sustained airway inflammation by suppressing ER stress response in a murine asthma remission model of respiratory syncytial virus infection. J Ethnopharmacol 192: 496-509, 2016.

31. Xia P, Gamble JR, Wang L, Pitson SM, Moretti PA, Wattenberg BW, D'Andrea RJ and Vadas MA: An oncogenic role of sphingosine kinase. Curr Biol 10: 1527-1530, 2000.

32. Cheng Q and Shang Y: ORMDL3 may participate in the pathogenesis of bronchial epithelial-mesenchymal transition in asthmatic mice with airway remodeling. Mol Med Rep 17: 995-1005, 2018.

33. Breslow DK, Collins SR, Bodenmiller B, Aebersold R, Simons K, Shevchenko A, Ejsing CS and Weissman JS: Orm family proteins mediate sphingolipid homeostasis. Nature 463: 1048-1053, 2010.

34. Nawijn MC, Hackett TL, Postma DS, van Oosterhout AJ and Heijink IH: E-cadherin: Gatekeeper of airway mucosa and allergic sensitization. Trends Immunol 32: 248-255, 2011.

35. Sweerus K, Lachowicz-Scroggins M, Gordon E, LaFemina M, Huang X, Parikh M, Kanegai C, Fahy JV and Frank JA: Claudin-18 deficiency is associated with airway epithelial barrier dysfunction and asthma. J Allergy Clin Immunol 139: 72-81.e1, 2017.

36. Hardyman MA, Wilkinson E, Martin E, Jayasekera NP, Blume C Swindle EJ, Gozzard N, Holgate ST, Howarth PH, Davies DE and Collins JE: TNF- $\alpha$-mediated bronchial barrier disruption and regulation by src-family kinase activation. J Allergy Clin Immunol 132: 665-675.e8, 2013.

37. Ma TY, Iwamoto GK, Hoa NT, Akotia V, Pedram A, Boivin MA and Said HM: TNF-alpha-induced increase in intestinal epithelial tight junction permeability requires NF-kappa B activation Am J Physiol Gastrointest Liver Physiol 286: G367-G376, 2004.

38. Qiu L: Effect of TNF- $\alpha$ on ORMDL3 gene promoter regulation and its possible mechanism. Dissertation, Nanjing Medical University, 2014.

39. Pitson SM, Moretti PA, Zebol JR, Xia P, Gamble JR, Vadas MA, D'Andrea RJ and Wattenberg BW: Expression of a catalytically inactive sphingosine kinase mutant blocks agonist-induced sphingosine kinase activation. A dominant-negative sphingosine kinase. J Biol Chem 275: 33945-33950, 2000.

40. Falsey AR, Hennessey PA, Formica MA, Cox C and Walsh EE: Respiratory syncytial virus infection in elderly and high-risk adults. N Engl J Med 352: 1749-1759, 2005.

41. Krishnamoorthy N, Khare A, Oriss TB, Raundhal M, Morse C, Yarlagadda M, Wenzel SE, Moore ML, Peebles RS Jr, Ray A and Ray P: Early infection with respiratory syncytial virus impairs regulatory $\mathrm{T}$ cell function and increases susceptibility to allergic asthma. Nat Med 18: 1525-1530, 2012.

42. Rezaee F, DeSando SA, Ivanov AI, Chapman TJ, Knowlden SA, Beck LA and Georas SN: Sustained protein kinase D activation mediates respiratory syncytial virus-induced airway barrier disruption. J Virol 87: 11088-11095, 2013.

43. Peebles RS Jr, Sheller JR, Johnson JE, Mitchell DB and Graham BS: Respiratory syncytial virus infection prolongs methacholine-induced airway hyperresponsiveness in ovalbumin-sensitized mice. J Med Virol 57: 186-192, 1999.

44. Wawrzyniak P, Wawrzyniak M, Wanke K, Sokolowska M, Bendelja K, Ruckert B, Globinska A, Jakiela B, Kast JI, Idzko M, et al: Regulation of bronchial epithelial barrier integrity by type 2 cytokines and histone deacetylases in asthmatic patients. J Allergy Clin Immunol 139: 93-103, 2017.
45. Sugita K, Steer CA, Martinez-Gonzalez I, Altunbulakli C, Morita H, Castro-Giner F, Kubo T, Wawrzyniak P, Rückert B, Sudo K, et al: Type 2 innate lymphoid cells disrupt bronchial epithelial barrier integrity by targeting tight junctions through IL-13 in asthmatic patients. J Allergy Clin Immunol 141: 300-310.e11, 2018.

46. Shang VC, Kendall DA and Roberts RE: $\Delta^{9}$-Tetrahydrocannabinol reverses $\mathrm{TNF} \alpha$-induced increase in airway epithelial cell permeability through $\mathrm{CB}_{2}$ receptors. Biochem Pharmacol 120: 63-71, 2016.

47. Hsu KJ and Turvey SE: Functional analysis of the impact of ORMDL 3 expression on inflammation and activation of the unfolded protein response in human airway epithelial cells. Allergy Asthma Clin Immunol 9: 4, 2013.

48. Ha SG, Ge XN, Bahaie NS, Kang BN, Rao A, Rao SP and Sriramarao P: ORMDL3 promotes eosinophil trafficking and activation via regulation of integrins and CD48. Nat Commun 4: 2479, 2013

49. Georas SN and Rezaee F: Epithelial barrier function: At the front line of asthma immunology and allergic airway inflammation. J Allergy Clin Immunol 134: 509-520, 2014.

50. Boussadia O, Kutsch S, Hierholzer A, Delmas V and Kemler R: E-cadherin is a survival factor for the lactating mouse mammary gland. Mech Dev 115: 53-62, 2002

51. Van den Bossche J and Van Ginderachter JA: E-cadherin: From epithelial glue to immunological regulator. Eur J Immunol 43: 34-37, 2013

52. Soini Y: Claudins in lung diseases. Respir Res 12: 70, 2011.

53. Niimi T, Nagashima K, Ward JM, Minoo P, Zimonjic DB, Popescu NC and Kimura S: Claudin-18, a novel downstream target gene for the T/EBP/NKX2.1 homeodomain transcription factor, encodes lung- and stomach-specific isoforms through alternative splicing. Mol Cell Biol 21: 7380-7390, 2001.

54. Ohta H, Chiba S, Ebina M, Furuse $M$ and Nukiwa T: Altered expression of tight junction molecules in alveolar septa in lung injury and fibrosis. Am J Physiol Lung Cell Mol Physiol 302: L193-L205, 2012.

55. Li G, Flodby P, Luo J, Kage H, Sipos A, Gao D, Ji Y, Beard LL, Marconett CN, DeMaio L, et al: Knockout mice reveal key roles for claudin 18 in alveolar barrier properties and fluid homeostasis. Am J Respir Cell Mol Biol 51: 210-222, 2014.

56. Abe-Yutori M, Chikazawa T, Shibasaki K and Murakami S: Decreased expression of E-cadherin by Porphyromonas gingivalis-lipopolysaccharide attenuates epithelial barrier function. J Periodontal Res 52: 42-50, 2017.

57. Montiel M, Quesada J and Jiménez E: Activation of calcium-dependent kinases and epidermal growth factor receptor regulate muscarinic acetylcholine receptor-mediated MAPK/ERK activation in thyroid epithelial cells. Cell Signal 19: 2138-2146, 2007

58. Roberts PJ and Der CJ: Targeting the Raf-MEK-ERK mitogen-activated protein kinase cascade for the treatment of cancer. Oncogene 26: 3291-3310, 2007.

59. Cohen TS, Gray Lawrence G and Margulies SS: Cultured alveolar epithelial cells from septic rats mimic in vivo septic lung. PLoS One 5: e11322, 2010.

60. Petecchia L, Sabatini F, Usai C, Caci E, Varesio L and Rossi GA: Cytokines induce tight junction disassembly in airway cells via an EGFR-dependent MAPK/ERK1/2-pathway. Lab Invest 92: 1140-1148, 2012

61. Lai WQ, Goh HH, Bao Z, Wong WS, Melendez AJ and Leung BP: The role of sphingosine kinase in a murine model of allergic asthma. J Immunol 180: 4323-4329, 2008.

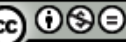

This work is licensed under a Creative Common Attribution-NonCommercial-NoDerivatives 4.0 International (CC BY-NC-ND 4.0) License. 